\title{
Positive Impact of Oregano Essential Oil on Growth Performance, Humoral Immune Responses and Chicken Interferon Alpha Signalling Pathway in Broilers
}

\author{
Azza Ahmed Abd El-Ghaffar Galal ${ }^{1 *}$, Iman El-Sayed El-Araby ${ }^{2}$, Ola Hassanin ${ }^{3}$, Anaam El- \\ SAID OMAR ${ }^{4}$
}

${ }^{1}$ Department of Pharmacology; ${ }^{2}$ Department of Animal Wealth Development; ${ }^{3}$ Department of Avian and Rabbit Medicine; ${ }^{4}$ Department of Nutrition and Clinical Nutrition, Faculty of Veterinary Medicine, Zaga20zig University, Zagazig 44511, Egypt.

\begin{abstract}
Supplementation of the herbal oils in poultry nutrition is considered an alternative and complementary approach to the conventional control viral strategies in poultry industry. Their use is associated with remarkable improvement in both bird performance and immunity. In the current study, one hundred twenty broiler chickens were allocated into four equal groups. Three groups (group B, C and D) were vaccinated with inactivated avian influenza and live LaSota vaccine and one group (group A) was left as a control non vaccinated group. Two groups, $\mathrm{C}$ and $\mathrm{D}$, were orally treated with 0.005 and $0.01 \%$ Oregano essential oil (OEO) respectively. Oral supplementation with a higher dose exerts improvement in the bird performance parameters in the early period of bird life and up to 21 days of age. Positive regulation of both NDV and AIV-HI specific antibody titers was existed when the birds were supplemented with the oil together with both NDV and AI vaccination, especially in case of the higher dose. Study of the effect of the OEO on chicken interferon-alpha signalling pathway components post NDV vaccination using quantitative real-time PCR (qRT-PCR) revealed no obvious positive immunomodulatory effect on Myxovirus resistance 1 (Mx1) transcripts level except at 29 days of age. On the other hand, a dose dependent up-regulation in both IFN regulatory factor 7 (IRF-7) and interferon-alpha RNA levels was observed. Both doses of OEO could protect the birds from nervous manifestation resulting from challenge with vvNDV. In conclusion, oral supplementation with OEO has beneficial effects on bird performance as well as humoral and innate immune responses.
\end{abstract}

Keywords | Oregano essential oil, Chickens; IRF7, INF- $\alpha$, qRT-PCR

Editor | Kuldeep Dhama, Indian Veterinary Research Institute, Uttar Pradesh, India.

Received | November 14, 2015; Revised | November 27, 2015; Accepted | November 29, 2015; Published | December 20, 2015

*Correspondence | Azza Ahmed Abd El-Ghaffar Galal, Zagazig University, Zagazig 44511, Egypt; E-mail: azzapharma@yahoo.com

Citation | Galal AAA, El-Araby IE, Hassanin O, Omar AE (2016). Positive impact of oregano essential oil on growth performance, humoral immune responses and chicken interferon alpha signalling pathway in broilers. Adv. Anim. Vet. Sci. 4(1): 57-65.

DOI | http://dx.doi.org/10.14737/journal.aavs/2016/4.1.57.65

ISSN (Online) | 2307-8316; ISSN (Print) | 2309-3331

Copyright (C) 2016 Galal et al. This is an open access article distributed under the Creative Commons Attribution License, which permits unrestricted use, distribution, and reproduction in any medium, provided the original work is properly cited.

\section{INTRODUCTION}

$\mathrm{N}$ ewcastle disease (ND) and avian influenza (AI) are considered the most serious diseases affecting poultry flocks worldwide. The both viruses are major concerns of bird husbandry causing severe economic losses to the poultry industry. These can be controlled by vaccinal strategies of birds at risk (Veits et al., 2006; Capua and Alexander, 2009). This successful intervention control strategy can be achieved by application of both live and inactivated virus vaccines (Gallili and Ben-Nathan, 1998; Swayne and King, 2003). Despite the wide use of the commercially available vaccines, in some cases, they are less effective for many reasons such as for immature or elderly individuals, environmental stress and immunosuppression (Beard and Mitchell, 1987; Saif, 1998; Maeda et al., 2004; Skowronski et al., 2008). Therefore, there is a necessity to improve the current immunization strategy applied with the both currently available ND and AI vaccines in order to enhance the host protection against virus infection. This improvement can be achieved by application of alternative and complementary approaches such as the usage of some 
natural herbal extracts.

Natural products have been used for their economical and medicinal values, including solving of many emerging health issues (Abdel-Daim et al., 2013; Abdel-Daim et al., 2014). There are growing evidences that medicinal herbs and their ingredients can enhance the immune responses to vaccination against infectious diseases (Liu and Xiao, 1992; Rajput et al., 2007). Co-administration of herbal extracts with vaccine showed an increase in antibody response as well as enhancement in the proliferative response of T cells (Hu et al., 2003; Sun et al., 2007). Furthermore, they can promote the effective use of feed nutrients which may subsequently result in rapid body weight gain (BWG), high production rates and improved feed efficiency (Ghazalah and Ali, 2008).

Large amounts of active constituents can also be found in essential oils of the medicinal plant. Essential oil of Origanum heracleoticum L (Syn.O. vulgare L) plant characterized by a high phenolic content (69.55\% Carvacrol and 4.09\% thymol) and two monoterpene hydrocarbons, $\gamma$-terpinene and cymol (3.05 and $10.57 \%$ of the total oil, respectively) (Mathlouth et al., 2012). Interestingly, oregano essential oil $(\mathrm{OEO})$ can exert an anticoccidial effect against Eimeria tenella (Giannenas et al., 2003), growth promoting effects, antioxidant activity, displayed potent antibacterial effects against cecal $E$. coli in broilers and improve broiler immune response (Roofchaee et al., 2011). Feed supplementation with thymol and carvacrol enhanced performance, increased antioxidant enzyme activities, retarded lipid oxidation, enhanced the activities of digestive enzymes, and improved immune response of broilers (Hashemipour et al., 2013).

Chickens exhibit a robust induction of type I interferons (IFNs) in response to infection by a variety viruses, such as NDV or AIV (Staeheli et al., 2001). Type I IFNs, $\alpha$ and $\beta$, serve as the primary trigger of a host's innate immune response against viral infection by stimulating a signaling pathway that includes more than 300 IFN-stimulated genes (ISGs) in mammals (Der et al., 1998) such as Myxovirus resistance 1 (Mx1), IFN-stimulated gene 15 (ISG15), IFN-stimulated gene 12 (ISG12) and 2'-5'-oligoadenylate synthetase (2'-5'OAS) and IRF-7 (Haller et al., 2007).

This study was planned to throw the light on the effect of commercially prepared OEO (Ropadiar ${ }^{\circledR}$ ) on the growth performance, humoral immune responses to ND and AI vaccines in broiler chicken. Furthermore, the expression of chicken interferon-alpha signaling pathway involved genes (Mx1, IRF7 and IFN-alpha) in the spleen of experimental birds was analyzed using quantitative RT-PCR.

\section{MATERIALS AND METHODS}

\section{Birds ANd DieT}

This study was carried out using 120 one-day-old Cobb chicks obtained from El-Shorouk Poultry Company. Birds were reared in a naturally ventilated open house with saw dust as litter and at a density $10 \mathrm{birds} / \mathrm{m}^{2}$. Continuous lighting was provided throughout the experiment. The starting temperature was $33^{\circ} \mathrm{C}$ then decreased gradually $2^{\circ} \mathrm{C}$ each week until reach $21^{\circ} \mathrm{C}$ at the $6^{\text {th }}$ week. Birds were fed on antibiotic free experimental diet, (Starter, grower and finisher) (Table 1) which formulated to meet the nutrient requirements set by the National Research Council (1994) and water supplied ad libitum.

Table 1: Physical and chemical composition (\%) of the experimental diets used in experimental stages

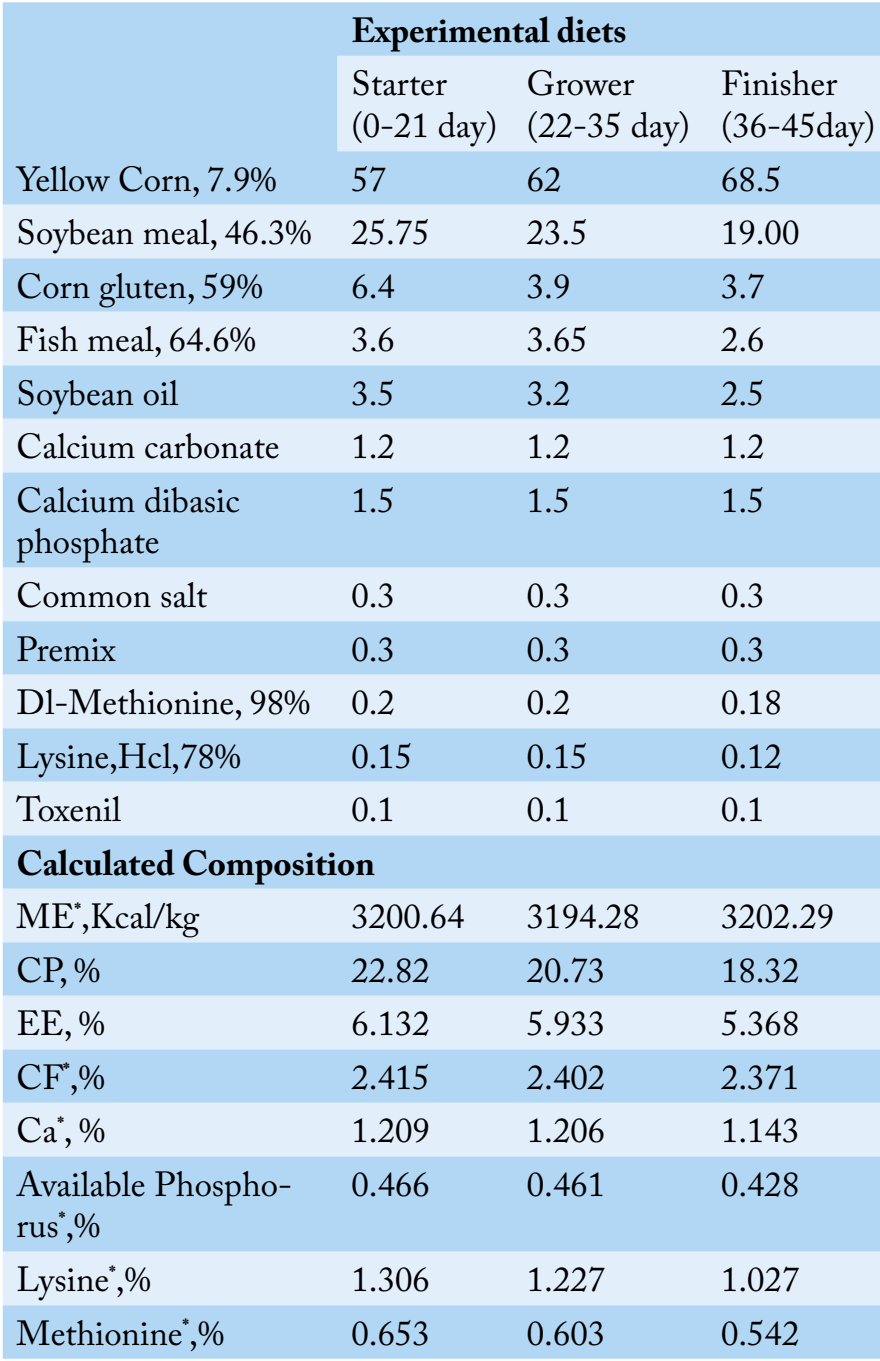

ME: Metabolizable energy; CP: Crude protein; EE: Ether extract; CF: Crude fiber; CP and EE were chemically analyzed according to procedures of AOAC (2002); "Calculated according to NRC (1994).

\section{ROPADIAR ${ }^{\circledR}$ SOLUTION $20 \%$}

This is the commercial preparation of $200 \mathrm{~g}$ Origanum essential oil ( $60.2 \%$ carvacrol+ $4 \%$ thymol), $200 \mathrm{ml}$ propylene 
glycol, $400 \mathrm{ml}$ polysorbate $80 \mathrm{E} 433$ and purified water up to 1 litre. It is a product of Ropapharm International, RondeTocht 481507 CK Zaandam - Netherlands.

\section{VACCINES}

$\mathrm{BIO} \mathrm{VAC}^{\circledast} \mathrm{ND}-\mathrm{IB}$, the freeze-dried live vaccine against Newcastle disease and infectious bronchitis, contains at least $10^{6.5}$ EID50 and $10^{3.5}$ EID50 of B1 strain of NDV and $\mathrm{H} 120$ strain of IBV respectively. CEVAC $^{\circledast}$ IBD L, contains the Winterfield 2512 strain of infectious bursal disease virus in live, freeze dried form. VOLVAC ${ }^{\circledast} \mathrm{AI}-\mathrm{ND}$, inactivated oil emulsified Avian Influenza virus Type A, subtype H5N2, A/CHICKEN/MEXICO/232/94/CPA strain and Newcastle Disease, minimum titer for Avian Influenza: $10^{7.6} \mathrm{EID} 50 /$ dose and for Newcastle: $10^{8.2} \mathrm{EID} 50 /$ dose. VOLVAC ${ }^{\circledast}$ ND LaSota MLV, freeze dried modified live virus vaccine, contains at least $10^{5.5} \mathrm{EID} 50 /$ dose.

\section{Experimental Design}

On arrival the chickens were weighed and randomly allocated into four equal groups; A, B, C and D. Each containing three replicates (10 chicksleach replicate). Birds of all groups were vaccinated via intraocular route $(\mathrm{I} / \mathrm{O})$ with BIO VAC ${ }^{\circledast}$ ND-IB vaccine and orally with the CEVAC ${ }^{\circledast}$ IBD $L$ vaccine at $2^{\text {nd }}$ and $12^{\text {th }}$ days of age, respectively. Birds of groups $(\mathrm{B}, \mathrm{C}$ and $\mathrm{D})$ were vaccinated with VOLVAC ${ }^{\circledast}$ $\mathrm{AI}-\mathrm{ND}(0.5 \mathrm{ml} \mathrm{s} / \mathrm{c}$ at the middle part of the neck $)$ and with VOLVAC ${ }^{\circledast}$ ND LaSota MLV (I/O) at the $9^{\text {th }}$ and $16^{\text {th }}$ day of age, respectively. Birds of groups $(\mathrm{C}$ and $\mathrm{D})$ were orally treated with 1 and $2 \mathrm{ml}$ of OEO /20 liter drinking water respectively $(0.005$ and $0.01 \%)$. The drug was used intermittently for 3 days (at age of 5-7, 15-17, 25-27 and 36-39 days). Five birds, from each group, were bled weekly at $17^{\text {th }}, 24^{\text {th }}, 31^{\text {th }}, 38^{\text {th }}$ and $45^{\text {th }}$ days of age from the wing vein and the blood was used for serum separation. Three birds of each group were slaughtered at $17^{\text {th }} 19^{\text {th }}$ and $45^{\text {th }}$ days of age and the spleens were immediately and aseptically removed for the RNA isolation. Birds were weighed at $1,8,15,22,29,36$ and $45^{\text {th }}$ day of age and the average weekly gain was calculated as the difference between two successive weekly weights of birds. The feed was weighed back on $8,15,22,29,36$ and $45^{\text {th }}$ day of the experiment. Total feed consumption and feed conversion ratio (feed intake: weight gain) were determined on the $45^{\text {th }}$ days of the experiment. Ten birds from each group were separated for the challenge experiment.

\section{Challenge with Velogenic Viscerotropic} NewCastle Disease Virus (vvNDV)

Ten birds from each group were challenged with vvNDV (Sheble and Reda, 1976) at $37^{\text {th }}$ day of age. The birds were challenged with $10^{6}$ EID50/IM/ bird and monitored for ten days post challenge to record the clinical signs and mortality rate.
Hemagglutination Inhibition (HI) Test

The micro-HI test was carried out using $8 \mathrm{HA}$ units of the LaSota vaccine strain of NDV and $4 \mathrm{HA}$ units of the AI (H5 subtype) hemagglutination inhibition test antigen (EGY/PR8-1 strain, HVRI) as well as 1\% chicken red blood cells. Serum samples were initially diluted into either $1 / 2$ or $1 / 5$ for AI or NDV, respectively, and a duplicate of twofold dilution series of each tested serum were prepared. $\mathrm{Ab}$ titers were expressed as log values of the highest reciprocal of the dilution which showed hemagglutination inhibition. All tested serum sample were pretreated at $56^{\circ} \mathrm{C}$ for 30 min to inactivate the non-specific agglutinin.

\section{RNA Isolation AND CDNA PREPARATION}

Total RNA was extracted from $30 \mathrm{mg}$ of spleen tissue using (RNA-spin ${ }^{\mathrm{TM}}$ cell and tissue RNA purification kit) (iNtRON) according to the manufacturer's protocol. The isolated RNA was transcribed into cDNA using Maxime RT PreMix kit (iNtRON) according to the manufacturer's instructions.

\section{Quantitative Real-Time PCR}

All amplifications were performed on a Rotor-Gene Q instrument (Qiagen, Germany). Relative gene expression levels of $\mathrm{Mx} 1, \mathrm{IFN} \alpha$ and IRF7 were quantified using $\beta$-actin as endogenous controls and normalized to the untreated control sample as a fold change and RealMOD ${ }^{\mathrm{TM}}$ Real-time PCR Master Mix Kit (2X). The amplification was performed using The quantitative PCR for Mx1, IFN $\alpha$, IRF7 and $\beta$-actin were performed using the specific forward and reverse primers indicated in Table 2. Before applying the reaction, a standard curve assay and a dissociation curve assay were performed to determine the amplification efficiency of the used primers and to investigate if there was any non-specific amplification, respectively.

Table 2: Sequence of the oligonucleotide primers used in quantitative real-time PCR

$\begin{array}{ll}\text { Gene } & \text { Sequences } \\ \text { IRF7 } & \text { F5'- CAG TGC TTC TCC AGC ACA AA -3' } \\ & \text { R5'- TGC ATG TGG TAT TGC TCG AT -3' } \\ \text { Mx1 } & \text { F5'- AAC GCT GCT CAG GTC AGA AT -3' } \\ & \text { R5'- GTG AAG CAC ATC CAA AAG CA -3' } \\ \text { IFNa } & \text { F5'- CCA GCA CCT CGA GCA AT -3' } \\ & \text { R5'- GGC GCT GTA ATC GTT GTC T -3' } \\ \beta_{-}- & \text {F5'- CCC CCG TGC TGT GTT CCC ATC TAT } \\ \text { actin } & \text { CG -3' } \\ & \text { R5'- GGG TGC TCC TCA GGG GCT ACT } \\ & \text { CTC AG -3' }\end{array}$

\section{Statistical Analysis}

The logarithm2 mean titer $(\log 2)$ of NDV and AIV-HI antibody responses to NDV and AIV as well as growth 
Table 3: Effect of both doses of OEO on body weight of broilers

\begin{tabular}{llllllll} 
Groups & \multicolumn{7}{c}{ Days } \\
& 1 & 8 & 15 & 22 & 29 & 36 & 45 \\
A & $50 \pm 0.00$ & $120 \pm 4.7^{\mathrm{b}}$ & $224 \pm 5^{\mathrm{c}}$ & $392 \pm 26.3^{\mathrm{b}}$ & $930 \pm 127.6$ & $1407 \pm 198$ & $1784 \pm 194.3$ \\
B & $52 \pm 1.2$ & $138 \pm 6.2^{\mathrm{a}}$ & $261 \pm 8.86^{\mathrm{b}}$ & $507 . \pm 47.6^{\mathrm{a}}$ & $979 \pm 94.6$ & $1452 \pm 96$ & $1904 \pm 104.7$ \\
C & $48 \pm 2$ & $128 \pm 4.6^{\mathrm{ab}}$ & $287 \pm 13.2^{\mathrm{ab}}$ & $518 \pm 27.4^{\mathrm{a}}$ & $947 \pm 72.4$ & $1303 \pm 123$ & $1774 \pm 72.7$ \\
D & $50 \pm 1.58$ & $142 \pm 3.7^{\mathrm{a}}$ & $297 \pm 12.1^{\mathrm{a}}$ & $467 \pm 17.2^{\text {ab }}$ & $810 \pm 84.3$ & $1210 \pm 124$ & $1835 \pm 159.6$
\end{tabular}

One hundred twenty chickens were allocated into equal four groups; A (non-vaccinated, non-treated), B (vaccinated, non-treated), while group $\mathrm{C}$ and $\mathrm{D}$ were vaccinated and orally treated with 0.005 and $0.01 \% \mathrm{OEO}$, respectively. The drug was used intermittently for 3 days (at age of 5-7, 15-17, 25-27 and 36-39 days). Birds were weighed at 1, 8, 15, 22, 29, $36+$ and $45^{\text {th }}$ day of age. Different letters indicate a significant difference with $(\mathrm{P} \leq 0.05)$.

Table 4: Effect of both doses of OEO on body weight gain of broilers

\begin{tabular}{lllllll} 
Groups & \multicolumn{5}{c}{ Weeks } \\
& 1 & 2 & 3 & 4 & 5 & 6 \\
A & $70 \pm 4.7^{\mathrm{b}}$ & $104 \pm 3.3^{\mathrm{b}}$ & $168 \pm 18.6$ & $538 \pm 89.9$ & $477 \pm 28.1$ & $377 \pm 54.7^{\mathrm{b}}$ \\
B & $86 \pm 6.2^{\mathrm{a}}$ & $123 \pm 12^{\mathrm{ab}}$ & $246 \pm 54.6$ & $472 \pm 50$ & $473 \pm 53.6$ & $452 \pm 50.3^{\mathrm{ab}}$ \\
C & $80 \pm 3.5^{\mathrm{ab}}$ & $159 \pm 16^{\mathrm{a}}$ & $271 \pm 55.7$ & $426 \pm 61.5$ & $357 \pm 72.27$ & $471 \pm 60.2^{\mathrm{ab}}$ \\
D & $92 \pm 4.6^{\mathrm{a}}$ & $155 \pm 15^{\mathrm{a}}$ & $170 \pm 17.1$ & $343 \pm 45.2$ & $380 \pm 65.45$ & $625 \pm 91.3^{\mathrm{a}}$
\end{tabular}

One hundred twenty chickens were allocated into equal four groups; A (non-vaccinated, non-treated), B (vaccinated, non-treated), while group $\mathrm{C}$ and $\mathrm{D}$ were vaccinated and orally treated with 0.005 and $0.01 \%$ OEO, respectively. The drug was used intermittently for 3 days (at age of 5-7, 15-17, 25-27 and 36-39 days). Birds were weighed at 1, 8, 15, 22, 29, 36 and $45^{\text {th }}$ day of age and the average weekly gain was calculated as the difference between two successive weekly weights of birds. Different letters indicate a significant difference with $(\mathrm{P} \leq 0.05)$.

Table 5: Effect of OEO on total feed consumption, total gain and total feed conversion ratio (FCR) in broilers

\begin{tabular}{llll}
\multicolumn{5}{c}{ Parameters } \\
Treatments & Total feed $(\mathrm{g})$ & Total gain $(\mathrm{g})$ & Total FCR \\
A & 3261 & $1734 \pm 194.3$ & $1.9 \pm 0.2$ \\
B & 3663 & $1852 \pm 104.9$ & $2 \pm 0.1$ \\
C & 3259 & $1764 \pm 99.1$ & $1.85 \pm 0.1$ \\
D & 3311 & $1765 \pm 160.5$ & $1.9 \pm 0.2$
\end{tabular}

One hundred twenty chickens were allocated into equal four groups; A (non-vaccinated, non-treated), B (vaccinated, nontreated), while group $\mathrm{C}$ and $\mathrm{D}$ were vaccinated and orally treated with 0.005 and $0.01 \%$ OEO, respectively. The drug was used intermittently for 3 days (at age of 5-7, 15-17, 25-27 and 3639 days). Feed was weighed back on 8, 15, 22, 29, 36 and 45 th day of the experiment. Total feed consumption and total feed conversion ratio (feed intake: weight gain) were determined at $45^{\text {th }}$ day of the experiment.

performance parameters were compared between groups via one way ANOVA test. The cytokine data were analyzed using Welch's $\mathrm{t}$-test.

\section{RESULTS}

Effects of OEO ON Chicken Growth Performance

A significant improvement on a bird's body weight was displayed by OEO treatment at 8,15 and 22 days of age
(Starter period) (Table 3). On the other hand, no growth trait was observed at 29, 36 and 45 days of age. At the $1^{\text {st }}$ and $2^{\text {nd }}$ week of age, the lower and higher dose treated birds had the highest and statistically significant weight gain $(\mathrm{P} \leq 0.05)$ compared with the control birds. Moreover, at the slaughter time the higher dose of OEO induced the highest and statistically significant weight gain $(\mathrm{P} \leq 0.05)$ compared with the control birds (Table 4). However, all the differently treated groups exerted nearly the same total feed intake, total BWG and total feed conversion ratio (Table 5).

\section{Effects of OEO on HI Antibody Responses Post NDV Vaccination}

As shown in Figure 1, the $\mathrm{OEO}$ treated groups $(\mathrm{C}$ and $\mathrm{D})$ had the highest statistically significant $(\mathrm{P} \leq 0.05) \mathrm{NDV}$ $\mathrm{HI}-\mathrm{Ab}$ titers compared with the control group at 7, 14, 21 and 28 days post NDV vaccination. The increase in NDV $\mathrm{HI}-\mathrm{Ab}$ titer was statistically significant $(\mathrm{P} \leq 0.05)$ at $28^{\text {th }}$ days post vaccination in lower dose treated group compared with group B. While the increases in NDV HI-Ab responses were statistically significant $(\mathrm{P} \leq 0.05)$ at 7,21 , 14 and up till 28 days post vaccination in Gp D compared with group A \& B. Marked increases in the HI-Ab responses, as early as 7 days post vaccination, when the birds administrated the higher dose of the oil compared with the lower dose. 


\section{Effects of OEO on HI Antibody Response Post} AI Vaccination

As shown in Figure 2, the OEO treated groups ( $\mathrm{C}$ and D) had the highest AI HI-Ab titers compared with the non-treated groups, at 22 and 29 days post vaccination. The higher dose of the oil exerted a higher immune response compared with the non-treated and lower dose treated groups, at 15 up till 36 days post vaccination.

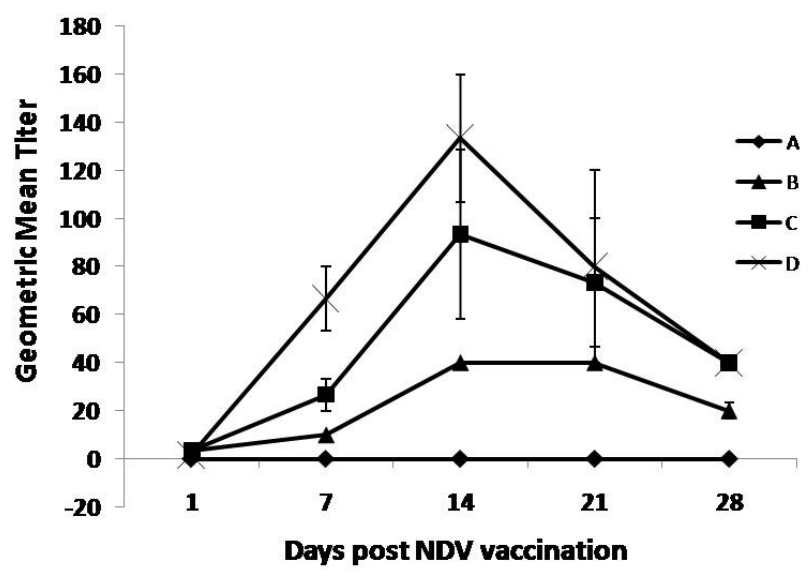

Figure 1: Specific NDV-Hemaaglutination inhibition Ab responses post NDV vaccination and treatment with OEO One hundred twenty birds were allocated into 4 groups. Chickens of group A were kept non vaccinated non treated and chickens of group B, C and D were vaccinated with live LaSota vaccine $(\mathrm{I} / \mathrm{O})$ at $16^{\text {th }}$ day of age. Chickens of groups $\mathrm{C}$ and $\mathrm{D}$ were vaccinated and orally treated with 0.005 and $0.01 \%$ OEO, respectively. The drug was used intermittently for 3 days (at age of 5-7, 15-17, 25-27 and 36-39).

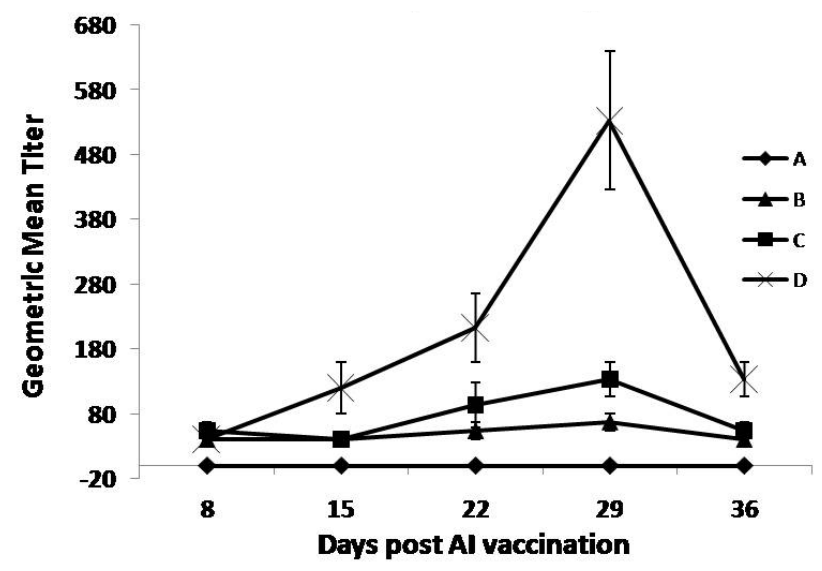

Figure 2: Specific AI-Hemaaglutination inhibition $\mathrm{Ab}$ responses post AIV vaccination and treatment with OEO One hundred twenty birds were allocated into 4 groups. Chickens of group A were kept non-vaccinated non-treated and chickens of group B, C and D were vaccinated with inactivated AI vaccine $(0.5 \mathrm{ml} \mathrm{s} / \mathrm{c}$ at middle part of the neck $)$ at $9^{\text {th }}$ day of age. Chickens of groups $\mathrm{C}$ and $\mathrm{D}$ were vaccinated and orally treated with 0.005 and $0.01 \%$ OEO, respectively. The drug was used intermittently for 3 days (at age of 5-7, 15-17, 25-27 and 36-39). a $\quad M \times 1$
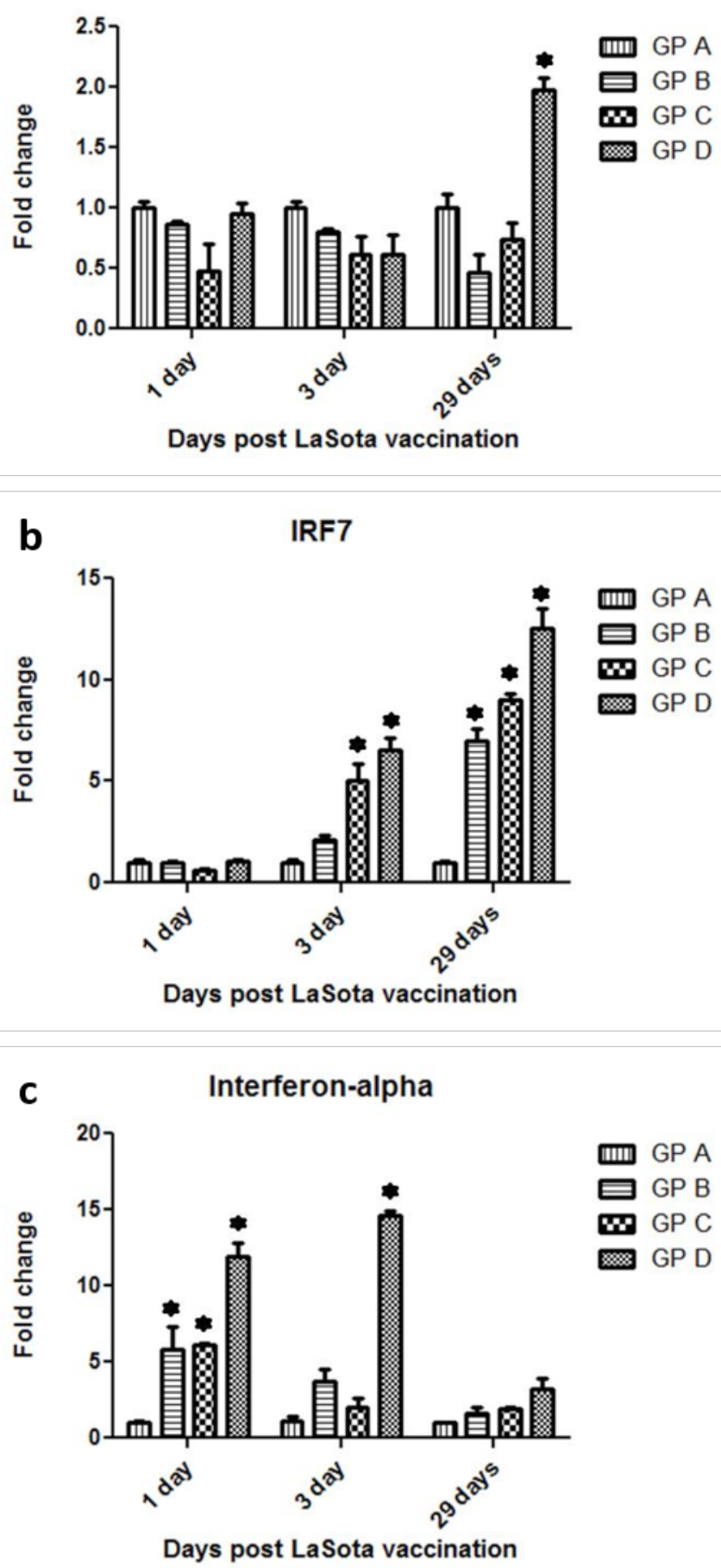

Figure 3: Gene expression of the interferon inducible genes Mx1 (a), INRF7 (b) and interferon-alpha (c) post $\mathrm{NDV}$ vaccination and treatment with $\mathrm{OEO}$

One hundred twenty birds were allocated into 4 groups. Chickens of group A were kept non-vaccinated non treated and chickens of group B Chickens of group A were kept non vaccinated non treated and chickens of group B, C and D were vaccinated with live LaSota vaccine $(\mathrm{I} / \mathrm{O})$ at $16^{\text {th }}$ day of age. Chickens of groups $\mathrm{C}$ and $\mathrm{D}$ were vaccinated and orally treated with 0.005 and $0.01 \%$ OEO, respectively. The drug was used intermittently for 3 days (at age of 5-7, 15-17, 25-27 and 36-39). Three birds of each group were slaughtered at $17^{\text {th, }} 19^{\text {th }}$ and $45^{\text {th }}$ day of age and the spleens were used for RNA isolation. The statistical analysis was done using Welch's $T$ test $\left({ }^{*} \mathrm{P}<0.001\right)$ 
EFfects of OEO ON CHICKEN INTERFERON-AlPHA Signalling Pathway Post NDV Vaccination

Three chickens of interferon-alpha signalling pathway components were selected to be analysed post NDV vaccination, Mx1 (antiviral gene), IRF7 (transcriptional factor and interferon inducible gene), Interferon-alpha (signalling inducer). No significant up-regulation in the Mx1 level was observed post NDV vaccination alone in all the measurable time points. However, at 29 days post vaccination, the high dose treated group $(\mathrm{GpD})$ exerted a higher level of Mx1 transcripts which was nearly about two fold up-regulation compared with the control group (Gp A) (Figure 3a). Regarding IRF7, NDV vaccination by itself (Gp B) exerted up-regulation in the IRF7 levels at 3 and 29 days post vaccination compared with the non-vaccinated group ( $\mathrm{Gp} A)$. This up-regulation was statistically significant $(\mathrm{P}<0.001)$ only at 29 days post NDV vaccination. The treatment of birds with OEO induced a dose dependent and statistically significant $(\mathrm{P}<0.001)$ up-regulation of IRF7 transcripts at 3 and up to 29 days post NDV vaccination (Figure $3 b)$. Vaccination with NDV by itself $(\mathrm{Gp} \mathrm{B})$ could induce a statistically significant elevation $(\mathrm{P}<0.001)$ in chicken interferon-alpha transcripts as early as $1^{\text {st }}$ day post vaccination. However, this elevation was transient and did not last up to $29^{\text {th }}$ day post NDV vaccination. Amongst the differently treated group, the highest level of chicken interferon-alpha level was detected in the higher dose treated \& NDV vaccinated bird $(\mathrm{Gp} \mathrm{D})$ at $1^{\text {st }}$ and $3^{\text {rd }}$ post NDV vaccination.

\section{Protective Effect of OEO and NDV} VACCINATION FROM Challenge WITH VVNDV

In order to evaluate the protective efficacy of the OEO in combination with NDV vaccination, ten birds from each group were infected with $10^{6}$ EID50 of vvNDV at $37^{\text {th }}$ day of age.

Ten days post challenge with vvNDV, with or without supplementation of OEO, all the Newcastle disease vaccinated birds with both live and inactivated vaccines had 100\% protection rate against challenge with the very virulent strain compared with the non vaccinated birds which had $100 \%$ mortality rate. However, only one bird from group B (vaccinated only) showed nervous manifestation in the 9th day post challenge.

\section{DISCUSSION}

Viral infection represents a major threat to poultry industry; hence many potential hazards can enhance the risk of it. One of those hazards is immunosuppression problem which can be arising from many reasons such as immunosuppressive infectious diseases, mycotoxin and excessive use of certain antibiotics. Therefore, the use of the naturally existed immunostimulants such as herbal essential oils may have a positive impact to reduce such problem and modulate the bird immune responses. This positive impact and immunomodulation effect of the herbal essential oils could be attributed to their antioxidant, antimicrobial and antiviral properties (El-Sheikh and Galal 2015; Abdel-Daim et al., 2015; Sokmen et al., 2004).

In the present study, the effects of oral supplementation of commercially prepared OEO (60.2\%carvacrol+ $4 \%$ thymol) on the bird immune system and body performance were studied. Two different doses were tested and compared together with the non-treated birds. Oral supplementation with the two different doses of OEO resulted in a significant improvement of the bird's body weight at 8 and 15 days of age as well as higher and statistically significant weight gain $(\mathrm{P} \leq 0.05)$ compared with control treated birds. The mechanism of phytobiotic essential oils for improving the productivity performance of broilers might be caused by improvements in feed utilization (Mocar et al., 2010), which promote better sedimentation of muscle proteins (Zheng et al., 2009), stimulation of appetite, digestive and absorption enzymes (Christaki et al., 2011) or the stimulating effect on Lactobacillus proliferation (Roofchaee et al., 2011). The results of the current study were strengthened by those of Hashemipour et al. (2013) who reported that, the dietary inclusion of thymol + carvacrol increases the body weight gain and feed efficiency.

In accordance to previous study which stated that thymol+carvacrol increased BWG from 1 to 42 days of age but decreased digesta viscosity (Hashemipour et al., 2014). Therefore, in addition to their antimicrobial activity (Wenk, 2000) thymol and carvacrol can significantly improve bird performance via their down regulatory effect on digesta viscosity (Hashemipour et al., 2014).

The results reported for total feed intake and total body weight gain in this study are in accordance with those of Roofchaee et al. (2011) who found that dietary supplementation of OEO to the broilers had no effect on total feed intake and total body weight gain.

The current study revealed that the highest NDV and AI, $\mathrm{HI}-\mathrm{Ab}$ responses were elicited when the birds were orally supplemented with OEO in the drinking water, especially in case of the higher dose $2 \mathrm{~m} 1 / 20$ liter drinking water. These results may be attributed to the potent antioxidant properties of thymol \& carvarcol combination that elevate the chicks' immune responses (Gabor et al., 2010; Feizi and Nazeri, 2011). Our results were strengthened by those of Hashemipour et al. (2013) who found that, continuous dietary application of thymol + carvacrol has a potential humoral immunostimulant activity in broilers by increasing hypersensitivity response, total and $\mathrm{IgG}$ anti-sheep red 
blood cell titers. Another study was performed to study the effect of Zataria multiflora essential oil (thymol and carvarcol combination) on NDV-HI specific Ab of broiler chickens (Mosleh et al., 2013). The authors of the later study concluded that Zataria multiflora essential oil induced a dose-dependent increase in NDV-HI specific $\mathrm{Ab}$ titers in an extent higher than levamisole, another potent immunostimulat.

Chicken cytokines, such as chicken interferon-alpha, are important compounds which are believed to play a role in the control of avian viral infection (Abdelwhab and Hafez, 2001). Currently, oral administration of chicken interferon alpha either alone or expressed in a vector considered as an alternative approach to control important avian viral infection such as NDV and Highly pathogenic influenza viruses (HPAIV) (Rahman et al., 2012). The interferon alpha mediated antiviral effect exerts from its downstream activation of interferon-alpha signaling pathway which leads to production of several interferon stimulated genes, such as IRF7, and virus restriction factors, such as Mx1. Therefore, in the present study, three gene were selected to be evaluated; chicken interferon alpha, chicken interferon regulatory factor 7 and $\mathrm{Mx} 1$ in respect to NDV vaccination and natural immunomodulator (OEO).

In the present study, the vaccination with NDV and treatment with OEO, induced a dose dependent up-regulation of IRF7 transcripts at 3 and up to 29 days post NDV vaccination. Additionally, chicken interferon-alpha transcripts of the same birds were detected as early as $1^{\text {st }}$ day post vaccination, but did not last up to $29^{\text {th }}$ day post NDV vaccination, especially in the higher dose treated birds $(\mathrm{Gp} D)$.

Despite of the early detection of the Mx1 transcripts in the differently treated groups, there was no significant up-regulation in the Mx1 level post NDV vaccination alone in all the measurable time points compared with the non-vaccinated birds. In a previous study, there was no detection of Mx1 transcripts in the spleen of live NDV vaccinated chickens (Hassanin et al., 2014). The latter could be explained by the differences in the vaccination schedule between the two studies.

Only, at 29 days post vaccination, the higher dose treated group $(\mathrm{GpD})$ exerted a higher level of $\mathrm{Mx} 1$ transcripts which was nearly about two fold up-regulation compared with the control vaccinated group which may be attributed to the effect of both inactivated AI vaccine and oregano essential oil treatment.

In this study, we have used a combination of live and inactivated NDV vaccine in order to imitate the field condition in the Egyptian poultry farms. Challenged vaccinated birds, either supplemented with OEO or not, had
$100 \%$ survival rate compared with the non-vaccinated birds which had 100\% mortality rate. On the other hand, supplementation of OEO could protect the bird from the appearance of clinical signs probably due to its immunomodulatory impact on releasing avian cytokines.

In conclusion, $\mathrm{OEO}$ has a positive regulatory effect on both bird performance and immune responses. The oral supplementation of $0.01 \%$ OEO has a positive impact on immune responses against vaccination with both $\mathrm{AI}$ and NDV vaccine. It can exert stimulation for the interferon-alpha signalling pathway components in the chicken spleen which considered as antiviral agents.

\section{ACKNOWLEDGEMENTS}

This research received no specific grant from any funding agency in the public, commercial, or not-for-profit sectors.

\section{CONFLICT OF INTERESTS}

The authors declare that they have no conflict of interests.

\section{AUTHORS' CONTRIBUTION}

All the authors contributed equally.

\section{REFERENCES}

-Abdel-Daim MM, Abuzead SM, Halawa SM (2013). Protective role of Spirulina platensis against acute deltamethrin-induced toxicity in rats. PLoS One. 8 (9):e72991. http://dx.doi. org/10.1371/journal.pone.0072991

-Abdel-Daim MM, Abd Eldaim MA, Mahmoud MM (2014). Trigonella foenum-graecum protection against deltamethrin-induced toxic effects on haematological, biochemical, and oxidative stress parameters in rats. Can. J. Physiol. Pharmacol. 92 (8): 679-685. http://dx.doi. org/10.1139/cjpp-2014-0144

-Abdel-Daim MM, Taha R, Ghazy EW, El-Sayed YS (2015). Synergistic ameliorative effects of sesame oil and alphalipoic acid against subacute diazinon toxicity in rats: haematological, biochemical and antioxidant studies. Can. J. Physiol. Pharmacol. 94(999): 1-8.

-Abdelwhab EM, Hafez MH (2012). Insight into alternative approaches for control of avian influenza in poultry, with emphasis on highly pathogenic H5N1. Viruses 4(11): 31793208. http://dx.doi.org/10.3390/v4113179

-AOAC (2002). Association official analytical chemists. Official Methods of Analysis. Gaithersburg, MD, U.S.A. Chapt. 4. Pp. 20-27.

- Beard CW, Mitchell BW (1987). Influence of environmental temperatures on the serologic responses of broiler chickens to inactivated and viable Newcastle disease vaccines. Avian Dis. 31:321-326. http://dx.doi.org/10.2307/1590879

- Capua I, Alexander DJ (2009). Avian influenza and Newcastle disease: a field and laboratory manual. Springer Verlag, Italy. http://dx.doi.org/10.1007/978-88-470-0826-7 
- Christaki E, Bonos E, Florou-Paneri P (2011). Comparative evaluation of dietary oregano, anise and olive leaves in laying Japanese quails. Braz J. Poult. Sci. 13: 97- 101. http://dx.doi. org/10.1590/s1516-635x2011000200003

- Der SD, Zhou A, Williams BR, Silverman RH (1998). Identification of genes differentially regulated by interferon alpha, beta, or gamma using oligonucleotide arrays. Proc. Natl. Acad. Sci. USA. 95(26):15623-15628. http://dx.doi.org/10.1073/pnas.95.26.15623

-El-Sheikh ESA, Galal AAA (2015). Toxic effects of sub-chronic exposure of malealbino rats to emamectin benzoate and possible ameliorative role of Foeniculum vulgare essential oil. Environ. Toxicol. Pharmacol. 39(3): 1177-88. http:// dx.doi.org/10.1016/j.etap.2015.04.008

- Feizi A, Nazeri M (2011). Thyme essential oils (Thymus vulgaris) alleviate vaccination reactions in broiler chickens. Ann. Biol. Res. 2:464-468.

- Gabor EF, Sara A, Barbu A (2010). The effects of some phytoadditives on growth, health and meat quality on different species of fish. Anim. Sci. Biotechnol. 43:61-65.

- Gallili GE, Ben-Nathan D (1998). Newcastle disease vaccines. Biotechnol. Adv. 16:343-366. http://dx.doi. org/10.1016/S0734-9750(97)00081-5

- Ghazalah AA, Ali AM (2008). Rosemary leaves as a dietary supplement for growth in broiler chickens. Int. Poult. Sci. 7: 234-239.

- Giannenas I, Florou-Paneri P, Papazahariadou M, Christaki E, Botsoglou NA, Spais AB (2003). Effect of dietary supplementation with oregano essential oil on performance of broilers after experimental infection with Eimeriatenella. Arch. Tierernahr. 57: 99-106.

- Haller O, Kochs G, Weber F (2007). Interferon, Mx, and viral countermeasures. Cytokine Growth Factor Rev. 18: 425433. http://dx.doi.org/10.1016/j.cytogfr.2007.06.001

- Hashemipour H, Kermanshahi H, Golian A, Veldkamp T (2013). Effect of thymol and carvacrol feed supplementation on performance, antioxidant enzyme activities, fatty acid composition, digestive enzyme activities, and immune response in broiler chickens. Poult. Sci. 92(8): 2059-69.

-Hashemipour H, Kermanshahi H, Golian A, Khaksar V (2014). Effects of carboxy methyl cellulose and thymol + carvacrol on performance, digesta viscosity and some blood metabolites of broilers. J. Anim. Physiol. Anim. Nutr. (Berl). 98(4):672-679.

-Hassanin O, Abdallah F, Awad A (2013). Effects of florfenicol on the immune responses and the interferon-inducible genes in broiler chickens under the impact of E. coli infection. Vet.

Res. Commun. 38(1): 51-58.

- Hu S, Concha C, Lin F, Persson WK (2003). Adjuvant effect of ginseng extracts on the immune responses to immunization against Staphylococcus aureus in dairy cattle. Vet. Immunol. Immunopathol. 91:29-37.

- Liu CX, Xiao PG (1992). Recent advances on ginseng research in China. J. Ethnopharmacol. 36: 27-38. http://dx.doi. org/10.1016/0378-8741(92)90057-X

-Maeda T, Shintani Y, Nakano K, Terashima K, Yamada Y (2004). Failure of inactivated influenza A vaccine to protect healthy children aged 6-24 months. Pediatr. Int. 46:122-125.

-Mathlouthi N, Bouzaienne T, Oueslati I, Recoquillay F, Hamdi M, Urdaci M, Bergaoui R (2012). Use of rosemary, oregano, and a commercial blend of essential oils in broiler chickens: In vitro antimicrobial activities and effects on growth performance. J. Anim. Sci. 90 (3): 813-23. http://dx.doi. org/10.2527/jas.2010-3646

- Mocar K, Stofan D, Angelovicva M, Liptaiova D (2010). The influence of feed mixtures with Origanum Aetheroleum on broiler's production in the application of the principles of welfare. Anim. Sci. Biotechnol. 43: 79- 83.

-Mosleh N, Shomali T, Aghapour Kazemi H (2013). Effect of Zataria multiflora essential oil on immune responses and faecal virus shedding period in broilers immunized with live Newcastle disease vaccines. Iran. J. Vet. Res. 14(3): 220-225.

-NRC (1994). Nutrient Requirements of Poultry. 9 $9^{\text {th }}$ Edn. National Academy Press, Washington, DC., USA., ISBN13: 9780309048927, Page. 155.

-Rahman MM, Uyangaa E, Han YW, Kim SB, Kim JH, Choi JY, Eo SK (2012). Oral co-administration of live attenuated Salmonella enterica serovar Typhimurium expressing chicken interferon- $\alpha$ and interleukin-18 enhances the alleviation of clinical signs caused by respiratory infection with avian influenza virus H9N2. Vet. Microbiol. 157(3-4):448-55. http://dx.doi.org/10.1016/j.vetmic.2011.12.029

-Rajput ZI, Hu SH, Xiao CW, Arijo AG (2007). Adjuvant effects of saponins on animal immune responses. J. Zhejiang Uni. Sci. 8: 153-61. http://dx.doi.org/10.1631/jzus.2007.B0153

-Roofchaee A, Irani M, Ebrahimzadeh MA, Akbari MR (2011). Effect of dietary oregano (Origanumvulgare L.) essential oil on growth performance, cecal microflora and serum antioxidant activity of broiler chickens. Afr. J. Biotechnol. 10(32):6177-6183

-Saif YM (1998). Infectious bursal disease and hemorrhagic enteritis. Poult. Sci. 77:1186-1189. http://dx.doi. org/10.1093/ps/77.8.1186

- Sheble A, Reda IM (1976). Isolation and characterization of a local velogenic viscerotropic strain of Newcastle disease virus M.V.Sc. Thesis, Faculty of Veterinary Medicine, Cairo University.

-Skowronski DM, Tweed SA, De Serres G (2008). Rapid decline of influenza vaccine-induced antibody in the elderly: Is it real, or is it relevant? J. Infect. Dis. 197:490-502.

-Sokmen M, Serkedjieva J, Daferera D, Gulluce M, Polissiou M, Tepe B, Akpulat H A, Sahin F, Sokmen A (2004). In vitro antioxidant, antimicrobial, and antiviral activities of the essential oil and various extracts from herbal parts and callus cultures of Origanum acutidens. J. Agri. Food Chem. 52(11): 3309-3312. http://dx.doi.org/10.1021/jf049859g

-Staeheli P, Puehler F, Schneider K, Gobel TW, Kaspers B (2001). Cytokines of birds: conserved functions-a largely different look. Journal of interferon \& cytokine research. J. Interferon Cytokine Res. 21(12):993-1010. http://dx.doi. org/10.1089/107999001317205123

-Sun J, Hu S, Song X (2007). Adjuvant effects of protopanaxadiol and protopanaxatriol saponins from ginseng roots on the immune responses to ovalbumin in mice. Vaccine. 25:11141120. http://dx.doi.org/10.1016/j.vaccine.2006.09.054

-Swayne DE, King DJ (2003). Avian influenza and Newcastle disease. J. Am. Vet. Med. Assoc. 222: 1534-1540. http:// dx.doi.org/10.2460/javma.2003.222.1534

-Veits J, Wiesner D, Fuchs W, Hoffmann B, Granzow H, Starick E, Mundt E, Schirrmeier H, Mebatsion T, Mettenleiter T C, Romer-Oberdorfer A (2006). Newcastle disease virus expressing $\mathrm{H} 5$ hemagglutinin gene protects chickens against Newcastle disease and avian influenza. Proc. Natl. Acad. Sci. USA. 103: 8197-8202. http://dx.doi.org/10.1073/ pnas.0602461103

-Wang J, Yang B, Hu Y, Zheng Y, Zhou H, Wang Y, Ma Y, Mao 
K, Yang L, Lin G, Ji Y, Wu X, Sun B (2013). Negative regulation of $\mathrm{Nmi}$ on virus-triggered type I IFN production by targeting IRF7.J. Immunol. 191(6):3393-9. http://dx.doi. org/10.4049/jimmunol.1300740

-Wenk C (2000). Recent advances in animal feed additives such as metabolic modifiers, antimicrobial agents, probiotics, and enzymes and highly available minerals. Review. Asian-Aus. J. Anim. Sci. 13:86-95.

-Zheng ZL, Tan JYW, Liu HY, Zhou XH, Xiang X, Wang KY (2009). Evaluation of oregano essential oil (Origanum heracleoticum $\mathrm{L}$.) on growth, antioxidant effect and resistance against Aeromonas hydrophila in channel catfish (Ictalurus punctatus). Aquaculture 292:214-218. http://dx.doi. org/10.1016/j.aquaculture.2009.04.025 